\title{
Factors Responsible for Utero-Vaginal Prolapse Among Women Attending at a District Hospital of Bangladesh
}

\author{
Shireen Akhter Khanam ${ }^{1 *}$ \\ Fahmida Rashid $^{2}$ \\ Shahnaz Sharmin \\ Kamrun Satter ${ }^{4}$ \\ Anjuman Nigad
}

\footnotetext{
'Department of Obstetrics \& Gynecology Rangamati Medical College Rangamati, Bangladesh.

${ }^{2}$ Department of Obstetrics \& Gynecology Chattogram Medical College Chattogram, Bangladesh.

${ }^{3}$ Department of Obstetrics \& Gynecology Chattogram Maa-O-Shishu Hospital Medical College Chattogram, Bangladesh.

${ }^{4}$ Department of Obstetrics \& Gynecology Cumilla Sadar Hospital

Cumilla, Bangladesh.

5 Department of Obstetrics \& Gynecology Chattogram General Hospital

Chattogram, Bangladesh.
}

*Correspondence to:

Dr. Shireen Akhter Khanam Associate Professor

Department of Obstetrics \& Gynecology Rangamati Medical College

Rangamati, Bangladesh

Mobile : +8801817 708042

Email:shireendr23@yahoo.com

Date of Submission : $\quad 05.05 .2019$

Date of Acceptance ： 11.08.2019

www.banglaiol.info/index.php/CMOSHMCJ

\begin{abstract}
Background : Utero vaginal prolapse is a big health problem in Bangladesh. The aim of this study was to calculate prevalence of uterine prolapse and to find out the possible factors that are responsible for this disease among patients attended at Chattogram General Hospital (250 bedded) Bangladesh.
\end{abstract}

Materials and methods: It was a descriptive study which was done between November 2016 to August 2017. This analysis was restricted to a sample that included all women complaints of uterine prolapse diagnosed and treated at Chattogram General Hospital.

Results: During a 10 months period, 100 women were diagnosed and treated with uterine prolapse. The prevalence of utero-vaginal prolapse is $4.2 \%$. The mean age at the time of clinical presentation was 40 years. In average, the women gave birth to four children vaginally. $20 \%$ of the women were smokers and $84 \%$ of them were postmenopausal. $10 \%$ of the affected patients had a Chronic Obstructive Pulmonary Disease (COPD) $41 \%$ suffered from hypertension and $15 \%$ had diabetes mellitus. The majority of the women with uterine prolapse reported that they were working heavily during perinatal period (78\%).

Conclusion : In this study several risk factors for uterine prolapse, specially extensive physical labor during pregnancy and immediately after delivery, 100\% unavailability of skilled births attendants, smoking while having COPD and low food adequacy during perinatal period are mainly responsible for this common disease.

Key words : Uterine prolapse; Factors responsible; Post partum period.

\section{INTRODUCTION}

Utero-vaginal prolapse is an abnormal herniation or protrusion of pelvic organs from its normal position in pelvis due to failure of anatomical support ${ }^{1}$.

The global prevalence of genital prolapse is estimated to be $2-20 \%$ in women under age 45 years $^{2}$. In fact, the exact prevalence of uterovaginal prolapse is difficult to be determined because many women are asymptomatic and many women feel shy or do not reveal the presence of uterovaginal prolapse due to social reason.

In Bangladesh, uterine prolapse appears to be wide spread, but little published evidence exists. The most commonly perceived cause of prolapse is lifting heavy loads, including in postpartum period. Most reports describe heavy household and farm working during pregnancy, as well as pre- and post-delivery, as the main causes and risk factors for this problem in Bangladesh. Similarly, lack of skilled birth attendants, frequent child birth and lack of nutritious food are also responsible ${ }^{1,3,4}$. Typically, most of the work is done manually, and household can not spare a woman's labor for any substantial length of time. Thus, women must recover fast from any condition that constrains their output ${ }^{4}$. 
Postmenopausal state due to hypoestrogenism and genital atrophy play the most important role in the pathogenesis of uterine prolapse. Patients with uterovaginal prolapse present with various symptoms like vaginal hernias or protrusion of mass through the introitus, urinary symptoms, vaginal discharge and difficulty in defecation.

The aim of this study was to identify possible risk factors for genital prolapse from patient attending Gynaecology Outpatient Department in Chattogram General Hospital, Bangladesh. Additionally, a brief discussion, comparing this disease with the epidemiology and responsible risk factors in other countries, presented.

\section{MATERIALS AND METHODS}

It was a descriptive study done on utero-vaginal prolapse at Chattogram General Hospital. Study population among the patients attending outpatient Department in this hospital from November 2016 to August 2017 (10 months).

A total of 100 women with uterine prolapse were included in this study. Most of these patients were diagnosed and treated at this hospital, some of them were diagnosed at outside and referred to this hospital.

All women with uterine prolapse reported adverse effects including abdominal pain, backache, painful intercourse, difficulty in voiding, white watery discharge, burning during urination and difficulty in lifting, sitting and standing.

Informations about the socio-demographic events was recorded on a precoded study form. Determinants of utero-vaginal prolapse including POPQ and treatment modalities also enrolled. The data were manually managed.

\section{RESULTS}

Hundred women with complaints of uterine prolapse were diagnosed and treated. $81 \%$ patients were diagnosed with second degree prolapse, $14 \%$ were first degree prolapse, while only $5 \%$ had third degree prolapse.

There was no nulliparous patients, $7 \%$ of women had more than 10 children. $81 \%$ were illiterate. The analysis of determinants and risk factors for utero-vaginal prolapse are shown in table III.

Clinical symptomatology and presentation are shown in table IV. The common presenting complaint of protruding a mass through introitus was $94 \%$. Next common complaint was urinary symptoms $57 \%$. Other symptoms were low backache $62 \%$. The predominant type of prolapse was uterine prolapse. Cystocele, cystocele \& rectocele and enterocele were present in $93 \%, 43 \% \& 3 \%$ respectively.

Staging of prolapse was done by POP-Q classification shown in table V.

Treatment modalities are shown in table VI.
Table I : Distribution of socio-demographic variables among the study subjects (n-100)

\begin{tabular}{|c|c|c|}
\hline & Variables & Frequency in \% \\
\hline \multirow[t]{3}{*}{ Age groups } & $<50$ years & $23 \%$ \\
\hline & $51-65$ years & $64 \%$ \\
\hline & $>65$ years & $13 \%$ \\
\hline \multirow[t]{3}{*}{ Education } & Illiterate & $81 \%$ \\
\hline & Primary & $11 \%$ \\
\hline & Secondary \& above & $08 \%$ \\
\hline \multirow[t]{2}{*}{ Occupation } & Labourer/service & $06 \%$ \\
\hline & Housewife & $94 \%$ \\
\hline \multirow[t]{2}{*}{ Age of marriage } & $<20$ years & $65 \%$ \\
\hline & $>20$ years & $35 \%$ \\
\hline
\end{tabular}

Table III : Parity of Respondents

\begin{tabular}{cc} 
Variables & Frequency in Percentage \\
\hline $1-2$ & $17 \%$ \\
$3-5$ & $41 \%$ \\
$6-9$ & $35 \%$ \\
$>10$ & $7 \%$ \\
\hline
\end{tabular}

Table III : Possible factors responsible for utero-vaginal prolapse $(\mathrm{n}=100)$

\begin{tabular}{llr} 
Variables & Yes & No \\
Home delivery with unavailability of SBA & 100 & 0 \\
Postmenopausal status & 84 & 16 \\
Heavy work during perinatal period & 78 & 22 \\
Food adequacy during perinatal period & 51 & 49 \\
Hypertension & 41 & 59 \\
Diabetes Mellitus & 15 & 85 \\
Smoking with COPD & 10 & 10 \\
\hline
\end{tabular}

Table IV : Clinical presentation of patients

\begin{tabular}{lc} 
Variables & Percentage \\
Uterine prolapse & $100 \%$ \\
Protrusion of mass per vagina & $94 \%$ \\
Cystocele & $93 \%$ \\
Low backache & $62 \%$ \\
Urinary symptoms & $57 \%$ \\
Cystocele and rectocele & $43 \%$ \\
Ulceration & $27 \%$ \\
Defecation difficulty & $13 \%$ \\
Enterocele & $3 \%$ \\
\hline
\end{tabular}

Table V : Staging of POP-Q

\begin{tabular}{lr} 
Stage & Percentage \\
Stage 0 & $3 \%$ \\
Stage I & $6 \%$ \\
Stage II & $6 \%$ \\
Stage III & $9 \%$ \\
Stage IV & $76 \%$ \\
\hline
\end{tabular}


Table VI : Treatment modalities of Respondents

\begin{tabular}{lr} 
Variables & Percentage \\
Vaginal hysterectomy with repair & $91 \%$ \\
Ring pessary & $4 \%$ \\
Conservative treatment & 3 \\
TAH with BSO with ant colporraphy & $2 \% \%$ \\
\hline
\end{tabular}

\section{DISCUSSION}

Pelvic organ prolapse is one of the most reproductive health problems in Bangladesh.

The most commonly reported causes for uterine prolapse in Nepal are extensive physical work, especially during and after pregnancy, unavailability of skill birth attendants and rapid succession of pregnancies and malnutrition due to lack of nutritious food ${ }^{1,3,4}$. The results of our report mainly confirmed these risk factors.

In our opinion, especially extensive physical labor during pregnancy and immediately after delivery, unavailability of SBA, smoking with COPD and lack of nutritious food are mainly responsible factors for this common disease. Typically, most of the heavy works and household done by the women. Most of the women do not even know why they have uterine prolapse and it can be treated because they are often too embarrassed to ask for help. In our study, most of the patients with prolapse were smokers. Smoking and uterine prolapse seem to be associated because chronic cough increases the pressure in the abdomen ${ }^{5}$. The most common cause of prolapse is lifting heavy loads. A study from Bakhtapur District reported, that $64.3 \%$ of women with uterine prolapse took rest at least 1 month after delivery, but $26.73 \%$ started working in field 2-3weeks after delivery ${ }^{6}$.

The global prevalence of genital prolapse is estimated to be 2$20 \%$ in women under age 45 years $^{1}$. Samuelsson et al. examined 487 women in Sweden ${ }^{7}$. The result of the study showed a prevalence of $30.8 \%$ uterine prolapse of any degree. Only $2 \%$ of all women had a prolapse that reached the introitus. In the study, patients' age, pelvic floor muscle strength and among parous women, maximum birth weight were significantly and independently associated with the presence of prolapse, whereas women's weight and sustained hysterectomy were not ${ }^{7}$.
Swift reported that advanced age, increasing parity, increasing number of vaginal births, delivery of a macrosomic infant, postmenopausal status and hypertension are associated with a statistically significant trend toward increased pelvic organ prolapse $^{8}$. The result of a study from Italy indicate that in this population, the risk of utero-vaginal prolapse increases with the number of vaginal births and is higher in over weight women 9 . In contrast to these studies, malnutrition is a dominant risk factor for uterine prolapse in Bangladesh and a great percentage of women with prolapse are of reproductive age having given birth to their first child. In summary, the prevalence as well as the defined risk factors for pelvic organ prolapse strongly differ between data from Europe/USA and Nepal.

There is significant association between number of vaginal deliveries, duration of labour, vaginal tear and sphincter damage in previous child delivery. $84 \%$ of women in our study were post menopausal. This result supported by the Indian study at Indira Gandhi Medical College, Pondicherry which showed a prevalance of $77 \%{ }^{10}$. This evidences that results in loss of collagen and weakness of fascia and connective tissue which is further aggravated in postmenopausal period due to estrogen deficiency leading to prolapse. Thus damage to pelvic floor muscles during delivery often becomes more evident when age related changes are superimposed. So patients had more than one risk factor which highlights the need for health programme for prediction and prevention of prolapse. Bulging is the principal symptom that correlates with prolapse severity. Majority of women had stage IV uterine prolapse. This could be because of the fact that women with prolapse usually do not present to the health care facility early as they are hesitant and worried about social implications.

\section{CONCLUSION}

Our data confirm that the most important factors responsible for uterine prolapse seem to be postmenopausal status, extensive physical labor during pregnancy and immediately after delivery, unavailability of skilled birth attendants, constipation, smoking with COPD and low food adequacy during perinatal period. Finally, awareness development during perinatal period, preventive care management and early treatment of genital prolapse should be initiated to reduce this significant public health problem.

DISCLOSURE

All the authors declared no competing interest. 


\section{REFERENCES}

1. Bonetti TR, Erpelding A, Pathak LR Listening to "felt need": investigating genital prolapse in western women Nepal. Reprod Health Matters. 2004;12 (23):166-175.

2. Westergren M, Falconer C, Bystrom B, Mamstrom A, Ekman G. Young women with genital prolapse have a low collagen concentration. Acta Obstet Gynecol Scand. 2004; 83:1193 -1198.

3. Center for Agro-Ecology and Development (CAED). Uterine prolapse widespread . Post Report. Nepal. 2004.

4. Subba B, Adhikari D, Battarai T. The neglected case of the fallen womb. Himal South Asian, Nepal. 2003.

5. Thapa S, Angdembe M, Chauhan D, Joshi R. Determinants of pelvic organ prolapse among the women of the western part of Nepal : A case control study . Journal of Obstetrics and Gynaecology Research. 2014; 40 (2): 515-520.

6. Marahatta RK, Shah A. Genital prolapse in women of Bakhtapur,Nepal . Nepal Med Coll J. 2003; 5 (1) : 31-33.

7. Samuelsson EC,Victor FT, T ibblin G, Svardsudd KF. Signs of genital prolapse ia Swedish population of women 20-59 years of age and possible related factors . Am J Obstet Gynaecol. 1999; 180: 299-305.

8. Swift SE. The distribution of pelvic organ support in a population of female subjects seen for routine gynaecologic health care. Am J Obstet Gynacol. 2002; 183(2): 27-28.

9. Progetto Menopausa Italia Study Group. Risk factors for genital prolapse in non-hysterectomized women around menopause . Results from a large cross-sectional study in menopausal clinics in Italy .Eur J Obstet Reprod Biol. 2000; 93 (2): 135-140.

10. Sujindra E, Himabindu N, Sabita P, Bhupathy A. Determinants and treatment modalities of utero vaginal prolapse : A retrospective study . Indian Journal of Health Sciences. 2015; 8(1): 36 . 